\title{
Microinjection of chemical carcinogens into small fish embryos: exocrine pancreatic neoplasm in Fundulus grandis exposed to $N$-methyl- $N$ '-nitro- $N$-nitrosoguanidine
}

\author{
John M. Grizzle ${ }^{1}$, Marshall R. Putnam ${ }^{2}$, John W. Fournie ${ }^{3}$, John A. Couch ${ }^{3}$ \\ ${ }^{1}$ Department of Fisheries and Allied Aquacultures, Auburn University, Auburn, Alabama 36849, USA \\ ${ }^{2}$ Department of Large Animal Surgery and Medicine, Auburn University, Auburn, Alabama 36849, USA \\ ${ }^{3}$ Environmental Research Laboratory, US Environmental Protection Agency, Sabine Island, Gulf Breeze, Florida 32561, USA
}

\begin{abstract}
Embryos of gulf killifish Fundulus grandis were injected with $N$-methyl- $N$-nitro- $N$ nitrosoguanidine (MNNG). Retention of carcinogen in the egg immediately after injection was highly variable. Hatching percentages of MNNG-injected and uninjected embryos were similar, but survival of MNNG-injected fish during the first week after hatching was less than half of the survival of controls. One of 3 MNNG-exposed fish examined after $20 \mathrm{wk}$ had a pancreatic acinar cell carcinoma, a type of neoplasm seldom found in fish. No neoplasms were recorded in controls nor in MNNG-exposed fish examined after $34 \mathrm{wk}$. The neoplasm was invasive and had a high mitotic index, but no metastases were found. The acinar cell origin of the tumor was confirmed by ultrastructural examination of tissue reprocessed from paraffin into epoxy resin
\end{abstract}

\section{INTRODUCTION}

Several species of fish are potentially valuable as laboratory animals in oncology. Couch \& Harshbarger (1985) reviewed numerous studies indicating that fish develop neoplasms after exposure to a variety of known carcinogens. For some fish models, neoplastic responses to chemical carcinogens resemble those of rodents (Couch \& Courtney 1987). Two major advantages to the use of fish as assay animals are evident: neoplasms can develop in less than 6 mo $(5$ to $8 \mathrm{wk}$ reported in some experiments), and spontaneous neoplasms are rarely found in control fish (Couch \& Harshbarger 1985). These features of fish assay systems indicate that they could be useful as alternative or complementary assays for carcinogenicity.

Experiments to develop carcinogenicity assays with fish embryos are desirable because embryos of some fish species are highly sensitive to the oncogenic effects of carcinogens. Rainbow trout Salmo gairdneri embryos appear to be the most sensitive model available for hepatocarcinogenicity of aflatoxin $B_{1}$ (AFB) (Hendricks et al. 1984). For some carcinogens, immersion of eggs in a solution containing the carcinogen has been successful in inducing neoplasia, but injection of chemical carcinogens into eggs offers advantages of more reliable penetration of the carcinogen into eggs and the need for a smaller quantity of test chemical (Metcalfe \& Sonstegard 1984, Metcalfe \& Sonstegard 1985, Black et al. 1985). However, fish embryos other than salmonids have not been adequately considered as test animals for experimental carcinogenesis.

The objectives of this project were to develop an injection method for small fish species and to determine the types of neoplasms resulting from injection of MNNG into gulf killifish embryos. Ultimately this could result in a method for assaying chemicals for carcinogenicity. MNNG is a direct acting carcinogen which causes several types of neoplasms in fish (Hendricks et al. 1980, Hyodo-Taguchi \& Matsudaira 1984, Brittelli et al. 1985, Chen et al. 1985), including hepatic tumors in salmonids exposed by embryo injection (Black et al. 1985).

\section{MATERIALS AND METHODS}

Microinjection equipment. Eggs were injected with the aid of a MSS100 microsurgery station (Micromanip- 
ulator Microscope Co.). This consisted of a low magnification, stereo microscope mounted on a metal base suitable for attaching magnetic based micromanipulators and micropipette systems. The base contained color contrast illumination and aperture-enhanced bright-field illumination systems. During injection, eggs were held by placing them in depressions in a Plexiglas plate. Each depression was approximately the same diameter and slightly shallower than the diameter of an egg.

Glass pipettes for injection were made from $1.2 \mathrm{~mm}$ outside diameter $(0.68 \mathrm{~mm}$ inside diameter) capillary tubing (Omega Dot Tubing). The tubing was heated and pulled with a microelectrode puller (Stoelting Co.) to obtain an end diameter of $95 \mu \mathrm{m}$. The injection pipettes were sharpened for 5 to $7 \mathrm{~min}$ on microabrasive paper ( $3 \mathrm{M}$ Co.) rotated at $78 \mathrm{rpm}$. During sharpening, the pipette was held in a Mycrolyte syringe (Micromanipulator Microscope Co.) in a micromanipulator so that a consistent angle could be maintained and water could be flushed through the pipette to prevent overheating.

Injection and rearing of gulf killifish. Adult female gulf killifish were injected intraperitoneally once daily for $2 \mathrm{~d}$ with 50 USP units of human chorionic gonadotropin (W. A. Butler Co.). Twenty-four hours after the second injection, eggs were stripped into a dry Petri dish, and then macerated testes and saltwater (30 ppt salinity) were added. The dish was swirled and allowed to stand for $7 \mathrm{~min}$. After 2 rinses, the eggs were transferred to glass culture dishes containing well-aerated saltwater. Water temperature ranged from 23 to $27^{\circ} \mathrm{C}$.

Embryos were injected $7 \mathrm{~d}$ postfertilization which was after liver formation. Before injection, eggs were rinsed in Hanks' balanced salt solution (HBSS) containing penicillin (100 $\left.\mathrm{IU} \mathrm{mi}^{-1}\right)$, streptomycin $\left(100 \mu \mathrm{g} \mathrm{ml}^{-1}\right)$, and amphotericin-B $\left(2 \mu \mathrm{g} \mathrm{ml}^{-1}\right)$. Sixty embryos were injected with $0.5 \mu \mathrm{l}$ of dimethylsulfoxide (DMSO) containing $2 \mu \mathrm{g}$ of MNNG (Sigma Chemical Co.). This was done by inserting a glass pipette through the chorion and into the yolk. Controls were DMSO-injected and uninjected embryos. After injection, eggs were rinsed in HBSS. Hatching occurred 12 to $13 \mathrm{~d}$ after fertilization.

After hatching, the fish were kept in flowing filtered water with salinity varying from 18 to $32 \mathrm{ppt}$. Test fish were fed a combination of newly hatched nauplii Artemia, frozen adult Artemia, and flake food once daily. Water temperature ranged from 14 to $25^{\circ} \mathrm{C}$. The low water temperature during the winter caused slow growth of the test fish.

Examination of test fish. Fish were fixed in either Davidson's or Bouin's solution $20 \mathrm{wk}$ or $34 \mathrm{wk}$ after injection. Whole fish were embedded in paraffin, sectioned sagittally, stained with Harris' hematoxylin and eosin, and examined by light microscopy.

A lesion in one paraffin-embedded specimen was prepared for transmission electron microscopy. This fish had been fixed in Davidson's fixative before paraffin embedding. The lesion remaining in the paraffin block was embedded in Spurr resin (Spurr 1969) after the paraffin had been removed with xylene. Sections were stained with uranyl acetate and lead citrate.

Quantification oi dose retained in eggs. Ten embryos were injected with a nominal dose of $0.5 \mu \mathrm{l}$ of $\left[{ }^{14} \mathrm{C}\right.$ ]benzoic acid (NEN Products) using the techniques described above. After injection each egg was rinsed in saline and then placed in a scintillation vial containing 1 $\mathrm{ml}$ of NCS tissue solubilizer (Amersham). After $24 \mathrm{~h}$ the eggs had dissolved, and the tissue solubilizer was neutralized with $0.05 \mathrm{ml}$ of glacial acetic acid. After addition of $10 \mathrm{ml}$ of OCS liquid scintillation cocktail (Amersham), the radioactivity in each vial was quantified with a liquid scintillation counter. Accuracy of the delivery system was determined by transferring $0.5 \mu \mathrm{l}$ labeled benzoic acid directly from the injection pipette into 10 scintillation vials. Percentage of the nominal dose retained in the egg was calculated by dividing the activity detected in the egg by the activity of the nominal dose.

\section{RESULTS}

Hatching percentage of MNNG-injected embryos was $63 \%$ compared with $67 \%$ for uninjected controls. Seven days after hatching only $32 \%$ of the MNNGinjected fish that had hatched were still alive compared with $69 \%$ and $83 \%$ of the DMSO-injected and uninjected controls, respectively.

Immediately after injection, the mean percentage of the nominal volume of $\left[{ }^{14} \mathrm{C}\right]$ benzoic acid detected in eggs was $3 \%$ (standard deviation, $5 \%$; range, 0 to $15 \%$ ). The difference between nominal volume and the amount measured in the eggs was not caused by inaccuracy of the syringe, which delivered $106 \%$ of the nominal volume (standard deviation, $6 \%$; range, 94 to $114 \%$ )

Figs. 1 to 3. Fundulus grandis. Paraffin sections of a pancreatic acinar cell carcinoma in a gulf killifish 20 wk after single injection of MNNG. The embryo has been injected in the yolk sac with MNNG $7 \mathrm{~d}$ after fertilization. Fig. 1. Low magnification of neoplasm. showing invasion and replacement of hepatic parenchyma $(\times 245)$. Fig. 2 . Relatively well differentiated reglon of tumor in which cells form distinct acini; note faintly granular cytoplasm and abnormal mitotic figure (arrowhead) ( $\times 555$ ). Fig. 3. Poorly differentiated area of tumor showing nuclear pleomorphism and desmoplastic stromal response; note mitotic figures (arrowheads) $(\times 370)$

Fig. 4. Transmission electron micrograph of a pancreatic acinar cell carcinoma previously embedded in paraffin; poorly preserved zymogen granules (arrowheads) and rough endoplasmic reticulum evident $(\times 8300)$ 

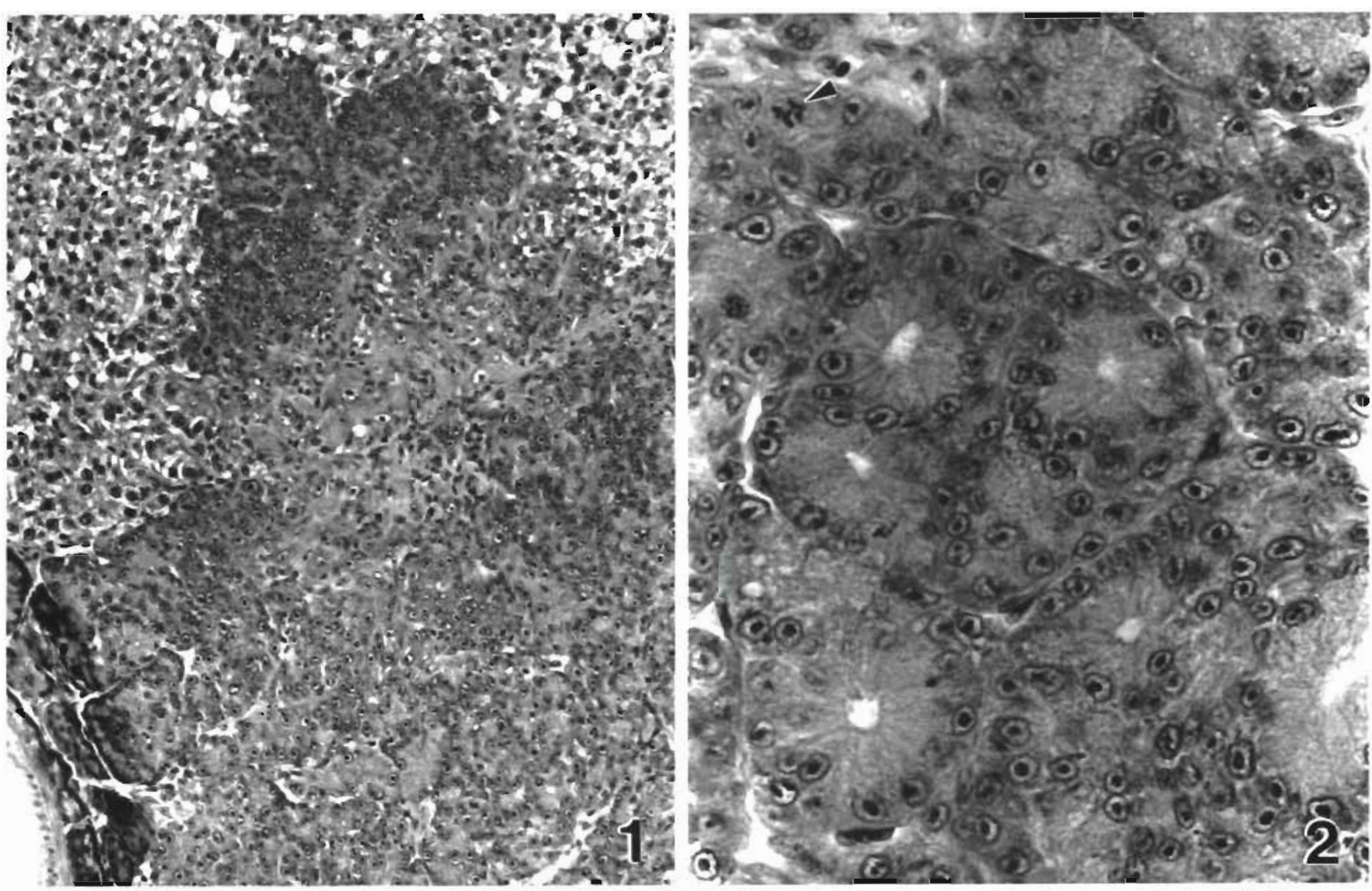

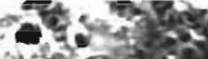

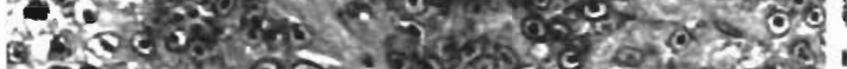
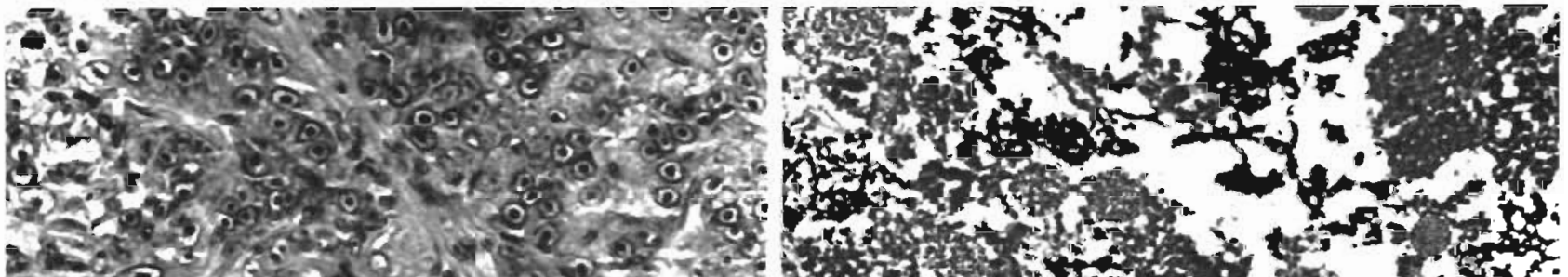

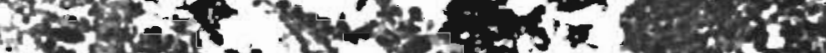

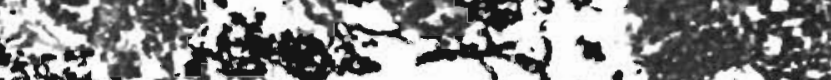
(5)

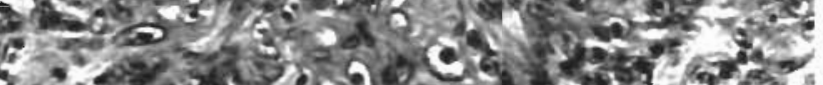

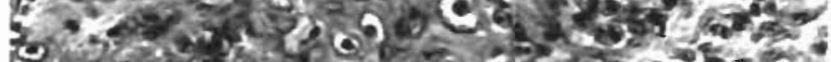

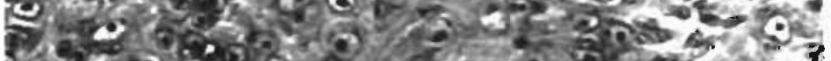

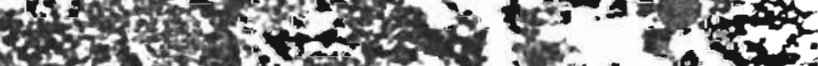

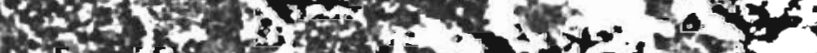

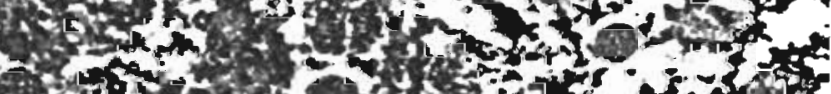

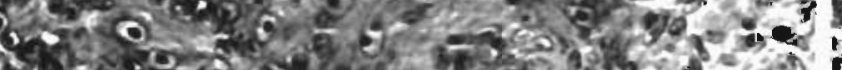

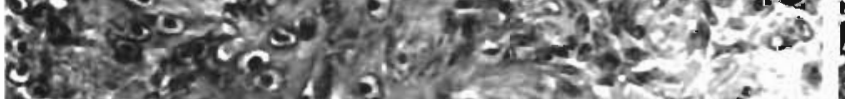

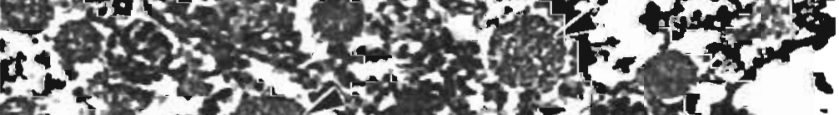

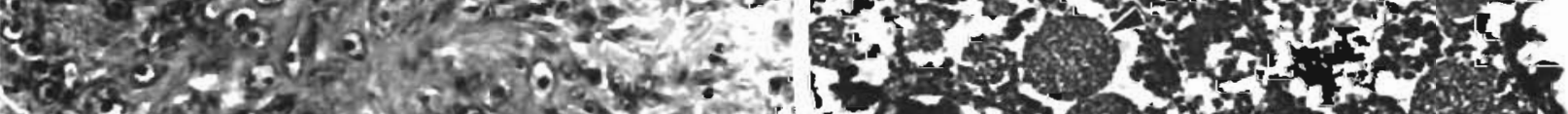

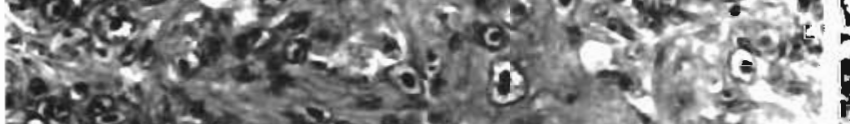

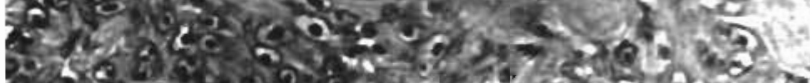

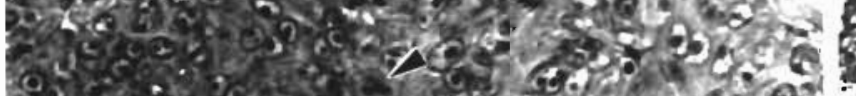
8. of 3.t.

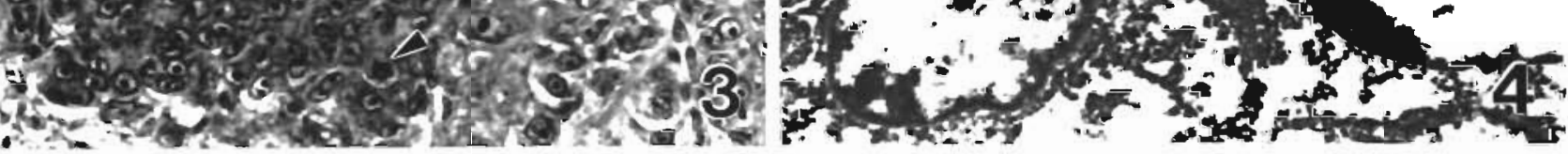


The exocrine pancreas of normal gulf killifish, including the control fish in this study, is scattered in the peritoneal cavity rather than forming a compact organ. Most of this gland is adjacent to hepatic portal veins and extrahepatic bile ducts near the liver and anterior intestine. The acinar cell cytoplasm is strongly basophilic except for the apical, eosinophilic zymogen granules. The spherical nuclei are basal and have a single, prominent nucleolus

A pancreatic acinar cell carcinoma was found in 1 of 3 gulf killifish killed 20 wk after injection of MNNG (Fig. 1). No other neoplasms or lesions considered potentially preneoplastic were found in these 3 fish, nor in the 3 MNNG-exposed fish killed after $34 \mathrm{wk}$. No lesions were found in the 8 control fish examined.

The acinar cell carcinoma was located in the mesentery and posterior portion of the liver. The tumor had invaded and replaced much of the hepatic parenchyma (Fig. 1). Most of the tumor was well differentiated, with the neoplastic cells resembling pancreatic acinar cells by exhibiting basal basophilia and apically placed eosinophilic granules. Cells tended to form acini with peripherally located nuclei (Fig. 2). The moderately pleomorphic nuclei contained 1 to 3 nucleoli. In less differentiated portions of the tumor, the nuclei were more pleomorphic and there was a desmoplastic response (Fig. 3). There were numerous normal and abnormal mitotic figures throughout the neoplasm. No metastases were found.

Ultrastructural examination confirmed the acinar cell origin of this neoplasm. The tumor cells contained numerous zymogen granules and abundant rough endoplasmic reticulum (Fig. 4).

\section{DISCUSSION}

There are only 2 previous reports of pancreatic neoplasms induced in fish by chemical exposure. In the present study, the pancreatic acinar cell carcinoma occurring in a gulf killifish Fundulus grandis exposed to MNNG supports previous studies indicating that pancreatic neoplasms are more likely to occur in fish exposed early in life. In a series of experiments in which rivulus were exposed to DEN at various ages after hatching, fish first exposed $1 \mathrm{~d}$ posthatching, but not those exposed $30 \mathrm{~d}$ posthatching, developed pancreatic adenocarcinomas (Thiyagarajah \& Grizzle 1986). Guppies Poecilia reticulata exposed to methylazoxymethanol acetate 6 to $10 \mathrm{~d}$ after birth developed pancreatic neoplasms (Foumie et al. 1987). The exposure of fish embryos seems promising as a method to induce pancreatic tumors. This could be used to resolve the questions about histogenesis of exocrine pancreatic carcinomas discussed by Fournie et al. (1987).
Initially, fish embryo exposures involved immersion of whole eggs into a test solution (Wales et al. 1978). This technique works well with slightly water-soluble carcinogens like $A F B$, and the single exposure to the carcinogen avoids the laboratory safety problems inherent during continuous exposures. However, immersion exposure is not suitable for highly water-insoluble chemicals such as benzola]pyrene (Hendricks et al. 1984). Immersion of whole eggs of non-salmonids in carcinogens has not been successful in inducing neoplasms. Embryo exposures of rivulus Rivulus ocellatus marmoratus to aqueous solutions of diethylnitrosamine (DEN) (Koenig \& Chasar 1984), brown bullhead Inctalurus nebulosus to AFB (Biba 1983), and sheepshead minnows Cyprinodon variegatus to trifluralin or AFB (Courtney \& Cuuch 1984) fátled to indice neoplasms.

Injection of carcinogens into fish eggs ensures exposure of the embryos to the test chemical, and this technique has been used with a variety of carcinogens to induce neoplasms in rainbow trout and coho salmon Oncorhynchus kisutch (Metcalfe \& Sonstegard 1984, Black et al. 1985, Metcalfe \& Sonstegard 1985). Injection with acetone or DMSO as carriers for test chemicals allows exposure of embryos to the highly waterinsoluble compounds benzo[a]pyrene and 7,12dimethylbenz(a)anthracene (Metcalfe \& Sonstegard 1984, Black et al. 1985). An additional advantage of injection is the diminutive amount of test chemical needed.

The incidence of lesions in this experiment was low compared with the numbers of hepatic tumors in rainbow trout exposed to AFB before hatching (Wales et al. 1978), but was similar to the incidence of hepatic tumors in rainbow trout and coho salmon exposed to MNNG by embryo injection (Black et al. 1985). The low percentage and high variation of the carcinogen dose retained in the egg immediately after injection could be related to the low incidence of tumors. The variation in retention of carcinogen could have resulted in survival of the fish that retained little of the dose. Other fish, injected with the same nominal dose, could have died because they retained a higher percentage. This would have biased the lesion-incidence data because it was not possible to determine which fish retained a high dose.

Retention of injected carcinogens was not a problem in the trout embryo injection assay (Metcalfe \& Sonstegard 1984); over $70 \%$ of the $\left[{ }^{3} \mathrm{H}\right]$ benzo[alpyrene injected into trout eggs was detectable by liquid scintillation $120 \mathrm{~h}$ postinjection. In proportion to egg size, a larger volume of fluid was injected into gulf killifish than into trout eggs. This proportionately larger volume or perhaps a less expandable chorion could be the cause of low retention of injected liquid in gulf killifish eggs. 
Although fish-embryo exposure appears to be a promising method to test new chemicals for carcinogenicity, the use of salmonids presents limitations such as exacting rearing conditions, long generation time, and difficulty in obtaining eggs outside of the natural spawning season (Hendricks et al. 1984). The relative merits of non-salmonid species for use in embryo-exposure models have not been adequately tested. There are many fish species free of the limitations listed above for the salmonid species.

Gulf killifish embryos have potential for use in carcinogenicity assays. This hardy species is easily spawned all year (Courtney \& Couch 1984) and is similar to Fundulus heteroclitus, one of the most thoroughly studies fish species. Although gulf killifish have apparent advantages as laboratory test animal for chemical carcinogen studies, they have seldom been used for this purpose (Hawkins et al. 1985). The eggs of this species are $2 \mathrm{~mm}$ in diameter (Simpson \& Gunter 1956), smaller than the eggs of salmonids previously used for embryo injection assays but larger than eggs of other species frequently used for experimental oncology. However, improvements in injection techniques are needed before an assay system involving injection of test chemicals into gulf killifish embryos can be used reliably.

Acknowledgements. We thank Scott White, Jocelyn Sindelar James Winstead, Lee Courtney, Cecily Pacoli, Lu Dureza, and Dehaj Xu for their technical assistance. This study was funded by cooperative agreement CR813425-01 with the US Environmental Protection Agency.

\section{LITERATURE CITED}

Biba, D. M. (1983). Effects of aflatoxin on the brown bullhead Ictalurus nebulosus. M. S. thesis. Auburn University, Auburn, Alabama

Black, J. J., Maccubbin, A. E., Schiffert, M. (1985). A reliable, efficient, microinjection apparatus and methodology for the in vivo exposure of rainbow trout and salmon embryos to chemical carcinogens. J. natn. Cancer Inst. 75: $1123-1128$

Brittelli, M. R., Chen, H. H. C., Muska, C. F. (1985). Induction of branchial (gill) neoplasms in the medaka fish (Oryzias latipes) by $N$-methyl- $N^{\prime}$-nitro- $N$-nitrosoguanidine. Cancer Res. 45: 3209-3214

Chen, H. H., Brittelli, M. R., Muska, C. F. (1985). Two cases of lymphosarcoma in channel catfish exposed to $\mathrm{N}$-methyl$N$-nitro- $N$-nitrosoguanidine. J. natn. Cancer Inst. 74. 933-939
Couch, J. A., Courtney, L. A. (1987). N-nitrosodiethylamineinduced hepatocarcinogenesis in estuarine sheepshead minnow (Cyprinodon variegatus): neoplasms and related lesions compared with mammalian lesion. J. natn. Cancer Inst. 79: 297-321

Couch, J. A., Harshbarger, J. C. (1985). Effects of carcinogenic agents on aquatic animals: an environmental and experimental overview. Environ. Carcinogenesis Rev. 3: 63-105

Courtney, L. A., Couch, J. A. (1984). Usefulness of Cyprinodon variegatus and Fundulus grandis in carcinogenicity testing: advantages and special problems. J. natn. Cancer Inst. Monogr. 65: 83-96

Fournie, J. W., Hawkins, W E., Overstreet, R. M., Walker, W W. (1987). Exocrine pancreatic neoplasms induced by methylazoxymethanol acetate in the guppy Poecilia reticulata. J. natn. Cancer Inst. 78: 715-725

Hawkins, W. E., Overstreet, R. M., Walker, W. W., Manning, C. S. (1985). Tumor induction in several small fish species by classical carcinogens and related compounds. In: Jolley, R. J., Bull, R. J., Davis, W. P. et al. (eds.) Water chlorination chemistry, environmental impact and health effects, Vol. 5. Lewis Publishers, Chelsea, Michigan, p. $429-438$

Hendricks, J. D., Scanlan, R. A., Williams, J. L., Sinnhuber, R. O. Grieco, M. P. (1980). Carcinogenicity of $N$-methyl- $N$ ' nitro- $N$-nitrosoguanidine to the livers and kidneys of rainbow trout (Salmo gairdneri) exposed as embryos. J. natn. Cancer Inst. 64: 1511-1519

Hendricks, J. D., Meyers, T R., Casteel, J. L., Nixon, J. E. Loveland, P. M., Bailey, G. S. (1984). Rainbow trout embryos: advantages and limitations for carcinogenesis research. Natn. Cancer Inst. Monogr. 65: 129-137

Hyodo-Taguchi, Y., Matsudaira, H. (1984). Induction of transplantable melanoma by treatment with $N$-methyl- $N^{\prime}$-nitro$N$-nitrosoguanidine in an inbred strain of the teleost Oryzias latipes. J. natn. Cancer Inst. 73: 1219-1227

Koenig, C. C., Chasar, M. P. (1984). Usefulness of the hermaphroditic marine fish, Rivulus marmoratus, in carcinogenicity testing. Natn. Cancer Inst. Monogr. 65: 15-33

Metcalfe, C. D., Sonstegard, R. A. (1984). Microinjection of carcinogens into rainbow trout embryos: an in vivo carcinogenesis assay. J. natn. Cancer Inst. 73: 1125-1132

Metcalfe, C. D., Sonstegard, R. A. (1985). Oil refinery effluents: evidence of cocarcinogenic activity in the trout embryo microinjection assay. J. natn. Cancer Inst. 75 : 1091-1097

Simpson, D. G., Gunter, G. (1956). Notes on habitats, systematic characters and life histories of Texas salt water Cyprinodontes. Tulane Stud. Zool. 4: 115-134

Spurr, A. R. (1969). A low-viscosity epoxy resin embedding medium for electron microscopy. J. Ultrastruct. Res. 26: $31-43$

Thiyagarajah, A., Grizzle, J. M. (1986). Diethylnitrosamineinduced pancreatic neoplasms in the fish Rivulus ocellatus marmoratus. J. natn. Cancer Inst. 77: 141-14

Wales, J. H., Sinnhuber, R. O., Hendricks, J. D., Nixon, J. E., Eisele, T A. (1978). Aflatoxin $B_{1}$ induction of hepatocellular carcinoma in the embryos of rainbow trout (Salmo gairdneri). J. natn. Cancer Inst. 60: 1133-1139 